\begin{tabular}{|c|}
\hline 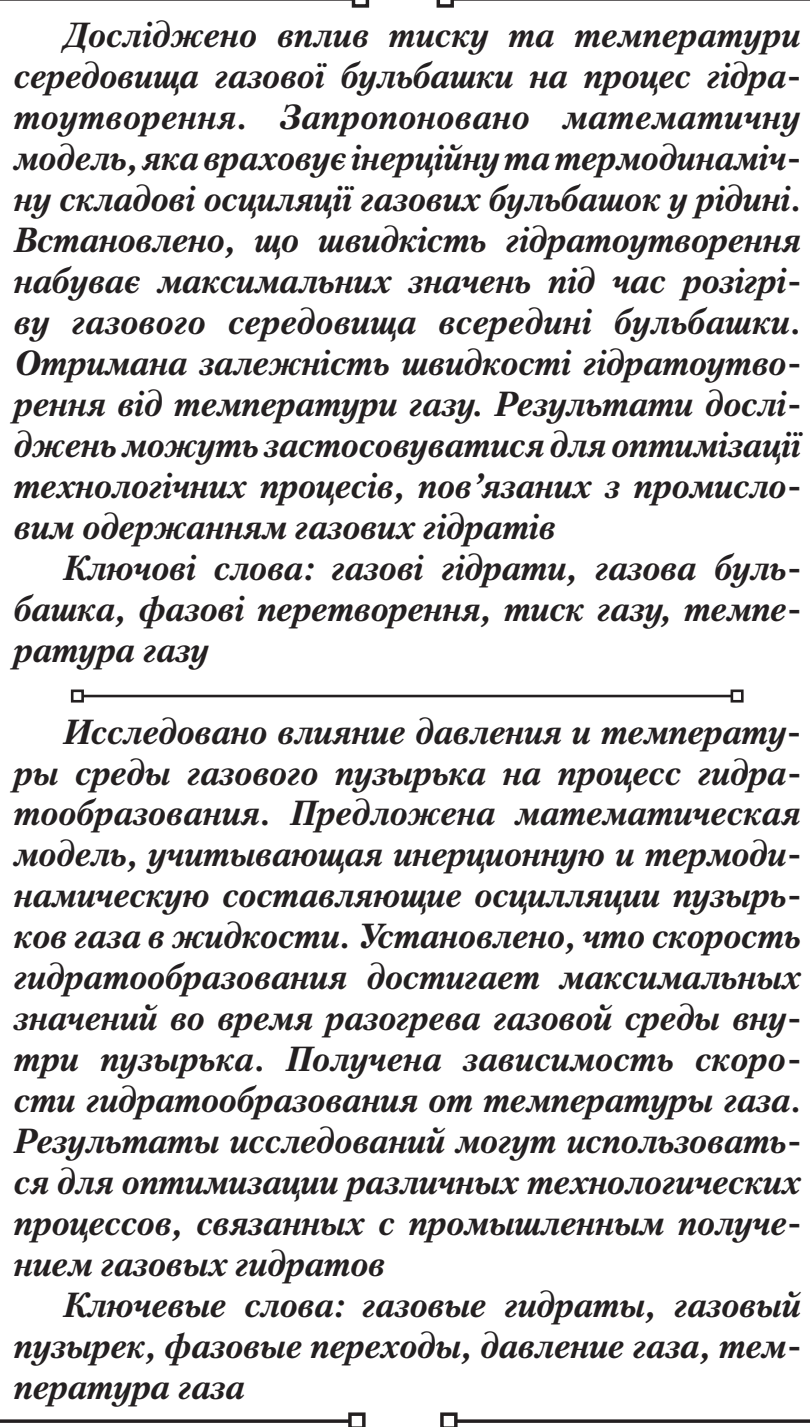 \\
\hline
\end{tabular}

1. Introduction

Thermodynamic processes, which occur on a surface of steam-and-gas bubbles, play a key role in many advanced industrial technologies. These are obtaining of hydrate of natural gas [1,2] for transportation and storage, desalination of seawater with a help of isobutane hydrate [3, 4], production of heat-insulating materials [5] by method of swelling, mixing of colloidal solutions, and many others.

It is convenient to transport and to store natural gas when it takes the form of gas hydrate. Under natural conditions and technological processes, formation of gas hydrates often occurs on a surface of gas bubbles in water under certain thermobaric conditions [6, 7]. A change in a composition of a gas, in a size of a bubble (oscillation), in temperature of a gas medium and a surface of a liquid accompanies the process of hydration. There is a very rapid change in thermodynamic parameters of the system "gas bubble - liquid - gas hydrate" during the oscillation. The study of the dynamics of phase transition processes on a surface of an oscillating gas bubble is relevant due to the need to optimize the technology of obtainment of gas hydrates.

Direct observation of processes inside a bubble during formation of gas hydrates is a complex engineering and tech-

\section{STUDY OF THE EFFECT OF THERMOBARIC CONDITIONS ON THE PROCESS OF FORMATION OF PROPANE HYDRATE}

A. Pavlenko

Doctor of Technical Sciences, Professor Department of Building Physics and Renewable Energy Kielce University of Technology

Tysiacholittia panstva Polskoho str., 7,

Kielce, Poland, 25-314

E-mail: apavlenko@tu.kielce.pl

B. Ku t n y i

$\mathrm{PhD}$, Associate Professor*

E-mail: kytnuba1@rambler.ru

Y u. Holi k

PhD, Professor*

E-mail: golik38@i.ua

*Department of heat and gas supply, ventilation and heat and power engineering Poltava National Technical Yuri Kondratyuk University Pershotravnevyi ave., 24, Poltava, Ukraine, 36011

nological problem. Such bubbles are small in size $\left(10^{-3} \div 10^{-4} \mathrm{~m}\right)$, they have high pressure (up to $20 \mathrm{MPa}$ ) and high oscillation rate (approximately $10^{-5} \mathrm{~s}$ ). Therefore, tools of mathematical modeling are widely used for the study of heat and mass transfer processes, which occur during hydration. However, such a mathematical model should take into account all thermodynamic peculiarities of this complex process.

\section{Literature review and problem statement}

Scientists widely use the Rayleigh-Plesset equation to analyze dynamics of oscillations of steam bubbles [8, 9] They often use Clapeyron-Clausius equations to determine a pressure inside a steam bubble [10,11], or consider a process as adiabatic process [12]. According to other scientists, processes inside an oscillating bubble are not limited to the phase transition or the lack of heat exchange on a surface of a bubble only. A mathematical statement of the problem is more complete in papers [13, 14]. In addition to the Rayleigh-Plesset equation, it contains the van der Waals equation for determination of a pressure inside a steam-andgas bubble and makes possible to calculate temperature of gases inside a bubble on the basis of the first law of thermo- 
dynamics. Also, transfer of heat and mass across the boundary of a bubble supplements a mathematical model. However, the mathematical model is designed for bubbles formed as a result of cavitation, and there is a highly discharged gas inside them. A paper [15] does not take into account phase transitions in a liquid, and in a work [6] a heat conductivity equation for a flat side describes a transfer of heat in a liquid, which surrounds a gas bubble. In determination of thermodynamic characteristics of a gas medium of a bubble, a number of authors take a constant temperature of a liquid: when calculating cavitation [10], gas [7] and steam [12] bubbles, swelling of materials [5].

To simulate processes of formation of gas hydrates, it is necessary to take into account a possibility of dissolving of bubble gases in a liquid with the simultaneous phase transition of a liquid into a solid phase (gas hydrate). A rate of heat and mass transition processes near a surface of a bubble determines the process of hydrate formation. Heat and mass transition processes, in turn, depend on a temperature and pressure of a gas mixture inside a bubble. Thermophysical characteristics of a liquid on a border with a bubble can also change significantly due to the hydrate formation. Thus, for the correct formulation of the problem, it is necessary to take into account a complex of interconnected mechanical and thermodynamic processes that proceed at high speed in a limited volume of a gas bubble.

\section{The aim and objectives of the study}

The objective of present work is to study the influence of initial temperature and pressure of the gas medium of a bubble on the processes of hydrate formation. This will make it possible to optimize the technology of industrial processes of hydrate formation. We set the following tasks to achieve the objective:

- to supplement a mathematical model of a gas bubble by a description of the diffusion processes on a gas-liquid boundary, of the phase transition and the hydrate formation processes in a liquid;

- to carry out calculations of transition thermodynamic processes inside an oscillating gas bubble and hydrate formation at different initial temperatures of the propane-butane mixture;

- to calculate the hydrate formation on a surface of a bubble at different initial pressures of a gas mixture and constant initial temperature of a gas.

\section{Mathematical model of bubble hydrate formation}

To obtain calculation data on a rate of hydrate formation on a surface of a gas bubble, we use a mathematical model, which contains the following simplifying assumptions:

- a gas bubble is spherical;

- a liquid is viscous and incompressible;

- there is a mixture of gases (propane and n-butane) inside a gas bubble, it's mass may change as a result of mass transition processes on a border of a bubble;

- we consider gases in a middle of a bubble as a real gas (taking into account the van der Waals forces) [13].

We consider equations, which describe the behavior of a steam-and-gas bubble in the transition to a new state of the thermodynamic equilibrium. We will record the inertial component of a gas bubble in a mathematical model with the help of the Relay-Plasset equation [8,9]

$$
\frac{d \dot{R}}{d \tau}=\frac{P_{B(\tau)}-P_{\infty}}{\rho_{r} R}-\frac{1.5}{R} \dot{R}^{2}-\frac{4 \mu_{r}}{\rho_{r} \cdot R^{2}} \dot{R}-\frac{2 \sigma_{r}}{\rho_{r} \cdot R^{2}},
$$

where $R$ is the radius of a gas bubble, $\mathrm{m}$; $\tau$ is time, $\mathrm{s} ; P_{B}$ is the pressure of a gas mixture inside a bubble, $\mathrm{Pa} ; P_{\infty}$ is the pressure in a liquid, $\mathrm{Pa} ; \rho_{r}$ is the liquid density, $\mathrm{kg} / \mathrm{m}^{3} ; \mu_{r}$ is the dynamic viscosity of liquid, $\mathrm{Pa} \cdot \mathrm{s} ; \sigma_{r}$ is the coefficient of surface tension of a liquid, $\mathrm{N} / \mathrm{m}$.

We can neglect a small amount of water steam in the propane-butane mixture. Then the radius of a bubble will change only at the expense of a radial movement of the bubble side. The velocity of the liquid $(\dot{R})$ at the boundary of a bubble can be determined by the formula

$$
\frac{d R}{d \tau}=\dot{R}
$$

The total pressure inside a bubble will be equal to the sum of partial pressures of individual gases according to the Dalton's law:

$$
P_{B}=P_{b}+P_{p},
$$

where $P_{b}, P_{p}$ are the partial pressures of butane and propane, respectively, $\mathrm{Pa}$.

The gas pressure varies widely in result of changes in a size, temperature and composition of the steam-and-gas mixture of a bubble. We use the van der Waals equation to take into account properties of real gases in the determination of pressure

$$
P_{b}=\frac{R_{\mu} T}{\frac{\mu_{b}}{\rho_{b}}-b_{b}}-\rho_{b}^{2} \frac{a_{b}}{\mu_{b}^{2}}, \quad P_{p}=\frac{R_{\mu} T}{\frac{\mu_{p}}{\rho_{p}}-b_{p}}-\rho_{p}^{2} \frac{a_{p}}{\mu_{p}^{2}},
$$

where $\rho_{b}, \rho_{p}$ are the densities of butane and propane, $\mathrm{kg} / \mathrm{m}^{3}$; $R_{\mu}=8314$ is the universal gas constant, $\mathrm{J} /(\mathrm{Kmol} \cdot \mathrm{K}) ; \mu_{b}$ is the a molecular weight of butane, $\mathrm{kg} / \mathrm{kmol} ; \mu_{p}$ is the molecular weight of propane, $\mathrm{kg} / \mathrm{kmol} ; T$ is the temperature of mixture of gases in a bubble, $\mathrm{K}$; $a$ is the constant of van der Waals, $\left(\mathrm{H} \cdot \mathrm{m}^{4}\right) / \mathrm{mol}^{2} ; b$ is the constant van der Waals, $\mathrm{m}^{3} / \mathrm{mol}$. Equation (4) can be replaced by modifications of the Van der Waals equation (Redlich-Kwong, Wilson or Soave) in some cases in order to improve the accuracy of a calculation.

It is necessary to know a density of gases inside a bubble at any given time to solve the equations (4). In the case of mass transition processes on a surface of a bubble, the density of each component of a gas mixture can be found by integrating of corresponding equations

$$
\frac{d \rho_{b}}{d \tau}=\frac{3}{R}\left(I_{b}-\rho_{b} \frac{d R}{d \tau}\right), \frac{d \rho_{p}}{d \tau}=\frac{3}{R}\left(I_{p}-\rho_{p} \frac{d R}{d \tau}\right),
$$

where $I_{b}, I_{p}$ are the masses of steam of butane and propane, which diffuse through a unit of a bubble surface per unit of time, $\mathrm{kg} /\left(\mathrm{m}^{2} \mathrm{~s}\right)$.

The first law of thermodynamics is used usually to determine temperature inside a steam bubble. For a mixture of two gases it looks as follows 


$$
\frac{d T}{d \tau}=\frac{3}{R\left(c_{b} \rho_{b}+c_{p} \rho_{p}\right)}\left[q-P_{B} \frac{d R}{d \tau}\right]
$$

where $c_{b}, c_{p}$ is the heat capacity of butane and propane, $\mathrm{J} /\left(\mathrm{kg} .{ }^{\circ} \mathrm{C}\right) ; q$ is the specific heat flow directed from a side to a gas medium of a bubble, $\mathrm{W} / \mathrm{m}^{2}$.

A prerequisite for the occurrence of a heat flow is the difference in temperature between a side of a steam bubble and a gas mixture in the middle of a bubble. The total specific heat flow $(q)$ consists of the following parts:

- a heat flow with molecules, which move from a gas mixture to a side of a bubble;

- a heat flow with molecules of gases, which were reflected from a side of a bubble and evaporated from it and move inside a bubble;

- a heat flow, which comes from a gas medium to a side of a bubble with gas molecules that are absorbed on this surface. In general, the equation for determination of the specific heat flow looks as:

$$
q=\left[\left(\frac{1}{6} \rho_{p} \bar{v}_{p(T)}+I_{p}\right) c_{p}+\left(\frac{1}{6} \rho_{b} \bar{v}_{b(T)}+I_{b}\right) c_{b}\right]\left(T_{(R, \tau)}-T\right),
$$

where $\bar{v}_{(T)}$ is the arithmetical mean velocity of gas molecules at $T$ temperature, $\mathrm{m} / \mathrm{s}$.

Formulas known from the molecular-kinetic theory of gases determine the arithmetical mean of heat motion of propane and butane molecules, $\mathrm{m} / \mathrm{s}$

$$
\bar{v}_{p(T)}=\sqrt{8 R_{\mu} T / \mu_{p} \pi} \text { and } \bar{v}_{b(T)}=\sqrt{8 R_{\mu} T / \mu_{b} \pi} \text {. }
$$

There are two known modes for determination of the mass flow at a surface of a bubble: diffusion and hydrate formation.

We can consider a rate of diffusion of propane and butane into water as constant when considering small intervals of time (about $200 \mu \mathrm{s}$ ). Then, based on Fick's first law, we determine the specific mass flow of diffusing gases by the formulas:

$$
I_{p}=-\frac{D_{p} P_{p}}{R \Gamma_{p}} \text { and } I_{b}=-\frac{D_{b} P_{b}}{R \Gamma_{b}},
$$

where $D_{p}, D_{b}$ are diffusion coefficients of propane and butane, respectively, $\mathrm{m}^{2} / \mathrm{s} ; \mathrm{H}_{p}, \mathrm{H}_{b}$ are the Henry constants for propane and butane, respectively $\left(\mathrm{Pa} \cdot \mathrm{m}^{3}\right) / \mathrm{kg}$. The sign "-” in formula (9) shows that a gas medium of a bubble "loses" a part of gas.

Since we have only a propane as a hydrate forming gas in the test mixture, we can determine the specific mass flow of this gas during the hydration process by the formula

$$
\Delta I_{p}=\frac{2 D_{p}}{R}\left(\rho_{g p}^{*}-\rho_{p}\right)
$$

where $\rho_{g p}^{*}$ is the propane density on a hydrate formation line, $\mathrm{kg} / \mathrm{m}^{3}$.

The density of the gas near a surface of the hydrate can be determined by the van der Waals equation

$$
\rho_{g p}^{*}=\frac{\mu_{p}}{\frac{R_{\mu} T}{P_{p}^{*}+\left(\rho_{g p}^{*}\right)^{2} \frac{a_{p}}{\mu_{p}^{2}}}+b_{p}},
$$

where $P_{p}^{*}$ is the propane pressure on a hydration line, $\mathrm{kg} / \mathrm{m}^{3}$.

We can use the Clapeyron-Clausius equation to determine this pressure near the surface of the hydrate

$$
P_{p(T)}^{*}=P_{S p} \exp \left[\frac{r_{g p} \mu_{p}}{R_{\mu}}\left(\frac{1}{T_{S p}}-\frac{1}{T_{(R, \tau)}}\right)\right],
$$

where $r_{g p}$ is the heat of the "hydrate - gas" phase transition, $\mathrm{J} / \mathrm{kg} ; P_{S p}, T_{S p}$ are the pressure and temperature of the reference point for gas, $\mathrm{Pa}, \mathrm{K}$. It is desirable to apply a working point with parameters characteristic for the middle of the working region of pressures and temperatures as a reference point. The heat of the phase transition can be considered as constant at slight changes in temperature (within $0 \div+5{ }^{\circ} \mathrm{C}$ for propane).

It is necessary to consider a process of heat transfer in a liquid to determine a temperature on the inner surface of a bubble. It occurs due to heat conductivity and convection. The Fourier heat equation is usually used to calculate the heat transfer by heat conduction. We can use an effective coefficient of a heat conductivity to calculate convection. Water can change its thermophysical characteristics (heat conductivity, density, heat capacity) in result of a heat exchange and phase transition processes at the boundary of a bubble, so we will solve the problem as nonlinear. Volumetric sources of heat make possible to take into account the heat of phase transitions.

If one marks a coordinate, which changes the radius of a bubble, as " $x$ ", the heat conductivity equation for a sphere with moving boundaries and volumetric sources of heat can be written as [16]

$$
\begin{aligned}
& \frac{\partial\left(\rho_{r} c_{r} T_{(x, \tau)}\right)}{\partial \tau}= \\
& =\frac{1}{x^{2}} \frac{\partial}{\partial x}\left(\lambda_{r} x^{2} \frac{\partial T_{(x, \tau)}}{\partial x}\right)-\dot{R} \frac{\partial\left(\rho_{r} c_{r} T_{(x, \tau)}\right)}{\partial x}+q_{v(x, T)},
\end{aligned}
$$

where $\rho_{r}$ is the liquid density, $\mathrm{kg} / \mathrm{m}^{3} ; c_{r}$ is the heat capacity of a liquid, $\mathrm{J} /\left(\mathrm{kg}^{\circ} \mathrm{C}\right) ; \tau$ is the time coordinate, $\mathrm{s} ; x$ is the rate of change in the radius of a bubble, $\mathrm{m} / \mathrm{s} ; \lambda_{r}$ is the effective coefficient of a heat conductivity of a liquid, $\mathrm{W} /\left(\mathrm{m}^{\circ} \mathrm{C}\right) ; q_{v}$ is the capacity of volumetric heat sources, $\mathrm{W} / \mathrm{m}^{3}$.

The influence of energy of various phase transitions (freezing/thawing, formation/dissociation of gas hydrate) is taken into account with the help of volumetric heat sources. The following formula determines the specific power of volumetric sources or heat losses

$$
q_{v(x, T)}=r_{g p} \frac{\partial}{\partial \tau}\left(\frac{\partial m_{g p}}{\partial V_{x}}\right)+r_{r} \frac{\partial}{\partial \tau}\left(\frac{\partial m_{r}}{\partial V_{x}}\right)
$$

where $r_{r}$ is the heat of the water-ice phase transition, $\mathrm{J} / \mathrm{kg}$; $m_{g p}$ is the mass of formed propane hydrate, $\mathrm{kg} ; m_{r}$ is the mass of ice formed during water freezing, $\mathrm{kg} ; \partial V$ is the elementary volume, $\mathrm{m}^{3}$.

Boundary conditions. Taking into account that the heat flow from a gas phase to a liquid (7) has a negative sign, we can write boundary conditions at the surface of a bubble as

$$
-\frac{\partial\left(\lambda_{r} T\right)}{\partial x}(R, \tau)=-q
$$


The boundary condition at a considerable distance from a center of a bubble, where the influence of other bubbles becomes equal,

$$
-\frac{\partial\left(\lambda_{r} T\right)}{\partial x}(x=\infty, \tau)=0
$$

\section{Initial time condition}

$$
T_{(x, \tau=0)}=T_{0} .
$$

The following conditions must be satisfied for hydrate formation:

- the partial pressure of the gas $P_{p}$ must exceed the minimum pressure of hydration $P_{g p}^{*}$ at the given temperature, $P_{p}>P_{g p}^{*}$

- the temperature of a liquid $T_{(x, \tau)}$ should be greater than $0{ }^{\circ} \mathrm{C}$, otherwise ice, and not hydrate, will be formed, but it should not exceed the temperature of hydrate formation for given partial pressure, $0<T_{(x, \tau)} \leq T_{g p}^{*}$. In the range $0 \div+5.5^{\circ} \mathrm{C}$, we can approximate temperature of hydrate formation of propane by the formula, $\mathrm{K}$

$$
T_{g p}^{*}=245.05+26 P_{p}^{0.15},
$$

where $P_{p}$ is the absolute propane pressure, atm.

We can solve the system of equations (1)-(18) with a use of digital methods, for example, the Runge-Kutta method of 4th order [17, 18]. We determine the mass of hydrate by the removal of heat from the phase transition from the hydrate formation region. For the hydration process (or its dissociation), we assume that the intensity of volumetric heat sources is linearly proportional to the temperature difference between a surface of the phase transition and temperature of the equilibrium state of the hydrate.

\section{Results of study of influence of pressure and temperature of a bubble gas medium on hydrate formation processes}

Let us consider heat-mass-exchange and hydrodynamic processes at the initial stage of a gas bubble introduction into water [19]. Such processes are technologically characteristic for the formation of hydrate of isobutane [3] and other hydrates [20,21]. We performed calculations of hydrate formation processes on the surface of bubbles with a diameter of $1 \mathrm{~mm}$ with a "winter" propane-butane mixture according to the proposed mathematical model. Output conditions: a gas bubble with a given initial temperature enters water at a temperature of $+2.5^{\circ} \mathrm{C}$ and a constant absolute pressure of 3.4 bar. We performed a series of calculations of the thermodynamic state of the gas bubble at various initial temperatures of the gas mixture to study the influence of the initial temperature of a gas on the hydration process.

The initial temperature of gases in the bubble can be either higher than the hydration temperature or less. Therefore, we will change a temperature of the gas from the beginning of hydrate formation to the freezing point of water on the surface of the bubble. Fig. 1 shows calculation results.

Row 1 corresponds to the gas temperature of $+3{ }^{\circ} \mathrm{C}$, which is $0.5^{\circ} \mathrm{C}$ higher than the hydration temperature at this pressure. Further increase of the temperature does not lead to the formation of hydrate for $200 \mu \mathrm{s}$. The heating of the gas in the bubble is delayed for a longer period. In general, a hydration process can only begin with a temperature of $+2.5^{\circ} \mathrm{C}$. The higher the initial temperature of a gas, the later a process of hydration formation will begin.

Row 2 corresponds to the initial temperature of $0.5{ }^{\circ} \mathrm{C}$ below the hydration temperature. It is seen that the hydrate formation process begins almost immediately and reaches maximum values during the heating of the bubble. We will take the number of hydrates formed at this temperature as a unit for comparison.

Row 3 corresponds to the initial temperature of $0{ }^{\circ} \mathrm{C}$. It is $2.5^{\circ} \mathrm{C}$ below the hydrate temperature. Obviously, there is a sharp increase in the amount of hydrate. The quantitative assessment gives a value of 6 times.

Row 4 corresponds to the initial temperature of $-5^{\circ} \mathrm{C}$. It is $7.5^{\circ} \mathrm{C}$ below the hydration temperature. There is also a sharp increase in the amount of hydrate. The quantitative assessment gives a value of 13 times.

Row 5 corresponds to the initial temperature of $-10{ }^{\circ} \mathrm{C}$. It is $12.5^{\circ} \mathrm{C}$ lower than the temperature of hydration. Further increase in the amount of hydrate is quite weak. The quantitative assessment gives a value of 15 times. This indicates that further cooling of a gas is ineffective. The reason for the ineffectiveness of further cooling is a freezing of deeper layers of a liquid and an increase in the resistance of a heat transfer. The deterioration of heat dissipation leads to a slow-down in the hydrate formation process.

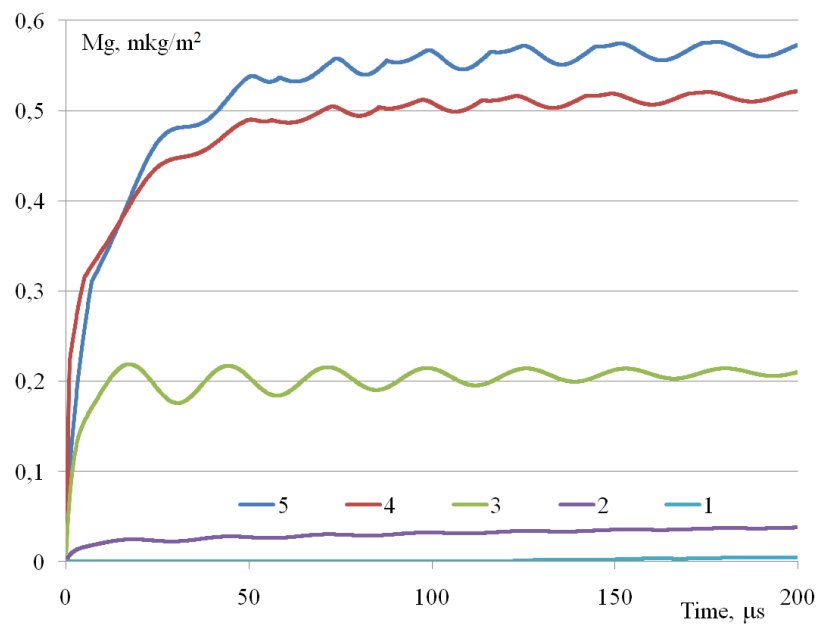

Fig. 1. Hydrate formation at different initial temperature of gas (row $1-t=+3{ }^{\circ} \mathrm{C}$; row $2-t=+2{ }^{\circ} \mathrm{C}$; row $3-t=0{ }^{\circ} \mathrm{C}$; row $4-t=-5{ }^{\circ} \mathrm{C}$; row $5-t=-10^{\circ} \mathrm{C}$ )

Fig. 2 shows graphs of temperature of the gas mixture in the middle of the bubble. Line 1 corresponds to the heated gas $\left(\right.$ to $\left.+3{ }^{\circ} \mathrm{C}\right)$. You can see cooling and a small oscillation, which overlaps it. Line 2 corresponds to the initial temperature of $+2{ }^{\circ} \mathrm{C}$. We can observe initial heating and small oscillations. Line 3 begins at $0{ }^{\circ} \mathrm{C}$ and rises rapidly at $2{ }^{\circ} \mathrm{C}$ in $5 \mu$ s. Then a fading oscillation process begins. Line 4 shows the process of heating of the medium of the bubble from the initial temperature of $-5{ }^{\circ} \mathrm{C}$. Line 5 corresponds to the heating process at the initial temperature of $-10{ }^{\circ} \mathrm{C}$.

Fig. 3 shows how the temperature distribution changes in time in liquid layers adjacent to the surface of the bubble. Each layer of the liquid has its thickness, Table 1. Layer 1 contacts the gas medium of the bubble directly, the center of layer 12 is in the liquid at a "depth" of almost $30 \%$ of the radius of the bubble. The thermal wave reached the 6 th layer ( $0.6 \%$ radius) in $200 \mu$ s according to Fig. 3 . 


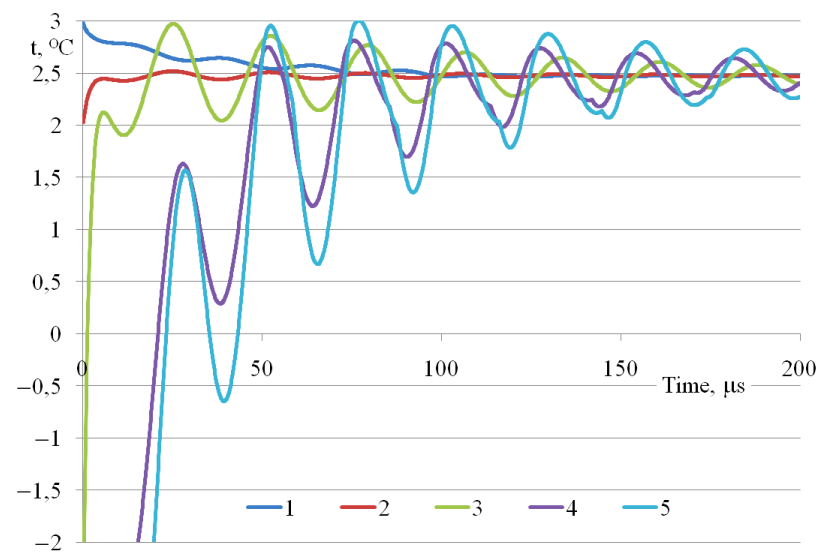

Fig. 2. Gas temperature in a bubble at various initial values row $1-t=+3{ }^{\circ} \mathrm{C}$; row $2-t=+2{ }^{\circ} \mathrm{C}$; row $3-t=0{ }^{\circ} \mathrm{C}$; row $4-t=-5{ }^{\circ} \mathrm{C}$; row $5-t=-10^{\circ} \mathrm{C}$

Table 1

Initial parameters of liquid layers

\begin{tabular}{|c|c|c|}
\hline Order number & $\begin{array}{c}\text { Radius of a center of } \\
\text { a layer, } \mathrm{mm}\end{array}$ & Average depth, \% \\
\hline 1 & 0.5 & 0 \\
\hline 2 & 0.500095 & 0.019 \\
\hline 3 & 0.500286 & 0.0566 \\
\hline 4 & 0.500668 & 0.1336 \\
\hline 5 & 0.501428 & 0.2856 \\
\hline 6 & 0.502943 & 0.5886 \\
\hline 7 & 0.505945 & 1.189 \\
\hline 8 & 0.511845 & 2.369 \\
\hline 9 & 0.523253 & 4.6506 \\
\hline 10 & 0.544685 & 8.937 \\
\hline 11 & 0.583110 & 16.622 \\
\hline 12 & 0.647610 & 29.522 \\
\hline
\end{tabular}

Fig. 4 illustrates the process of hydrate formation in the liquid layer, which surrounds the oscillating bubble. It can be seen that the hydration process takes place only in the first layer, which has a thickness of only $0.016 \%$ of the radius of the bubble, throughout the entire time interval. The hydrate formation is the most intense during the heating of gas bubbles. Then the process slows down and may be accompanied by partial dissociation during fading oscillations of the bubble.

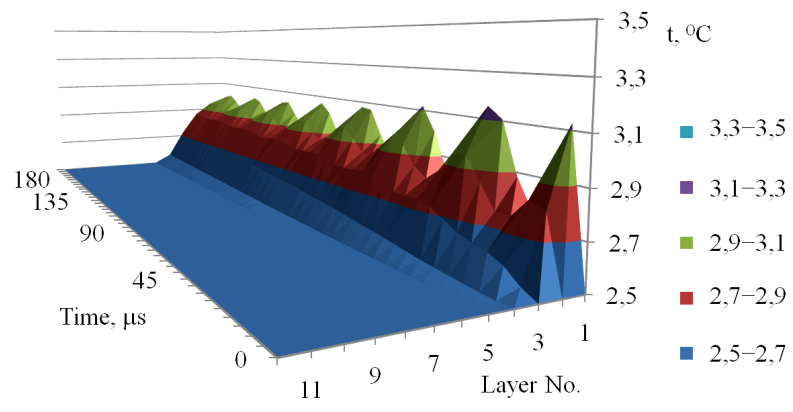

Fig. 3. Temperature of water layers at the initial temperature of $0{ }^{\circ} \mathrm{C}$

Let us analyze the influence of the initial gas pressure on the hydrate formation process. It is known that when pressure is insufficient, a hydrate formation process will not occur at all. However, what will happen when pressure is raised above the minimum required for a hydration process at a given temperature? We conducted a number of mathematical experiments on a model to clarify this issue. Fig. 5 shows the calculation results for various gas pressures.

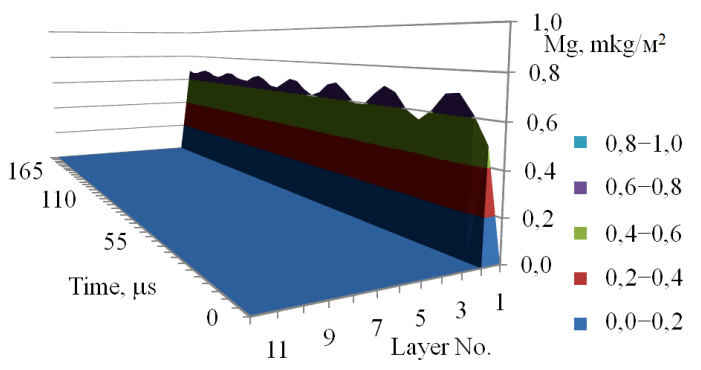

Fig. 4. Hydrate formation at the initial temperature of $0{ }^{\circ} \mathrm{C}$

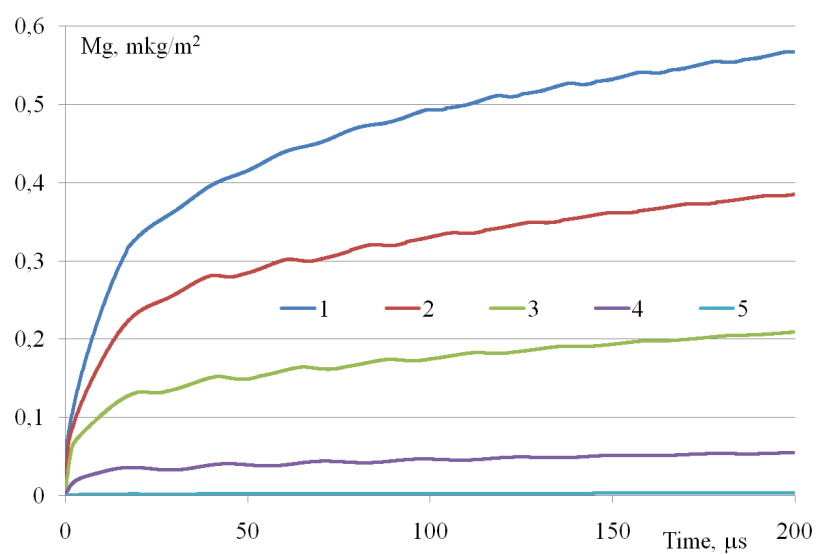

Fig. 5. Hydrate formation at different initial pressures (P bar) $1-P=P_{\min }+1.5 ; 2-P=P_{\min }+1 ; 3-P=P_{\min }+0.5$; $4-P=P_{\min }+0.1 ; 5-P=P_{\min }$

We can conclude from Fig. 5 that the amount of formed hydrate increases in proportion to pressure in a gas-water system. Comparing Fig. 5 and 1, it can be seen that when pressure of the oscillation of a bubble increases, the hydrate formation process is less influenced by temperature of a gas. In addition, it is evident that when the temperature of a gas decreases, the hydration process is more intense at the first $60 \mu \mathrm{s}$, and then slows down sharply. In the case of an increase in pressure in the initial region (up to $60 \mu \mathrm{s}$ ), the process of hydrate formation is slower, but its intensity does not fall in time as quickly as when the temperature of a gas decreases.

Fig. 6 illustrates the temperature regime of the gas medium of the bubble. The temperature of hydrate formation increases with increase in pressure, there is an intense heat emission due to hydrate formation. This leads to the heating of the surface of the bubble and occurs due to the intense heat transfer of the rapid increase in the temperature of a gas in the bubble. We can observe such intensive heating of a gas of the bubble at a short time interval of $20-60 \mu$ s (depends on pressure) only. Then there are fluctuations in the temperature of a gas, which are the result of fading oscillations of the bubble.

Fig. 7-9 present the process of formation of hydrate in liquid layers for various pressures. The first layer was filled with hydrate only by half during the calculated period under 
conditions of minimum pressure (Fig. 7). The first layer is filled completely with hydrate, and the second one is filled by about half at an excess pressure of 0.5 bar (Fig. 8). Further increase of excess gas pressure leads to an increase in the thickness of the hydrate layer around the bubble. Fig. 9 shows the first and second layers of the liquid filled with hydrate, and the third is filled by $25 \%$.

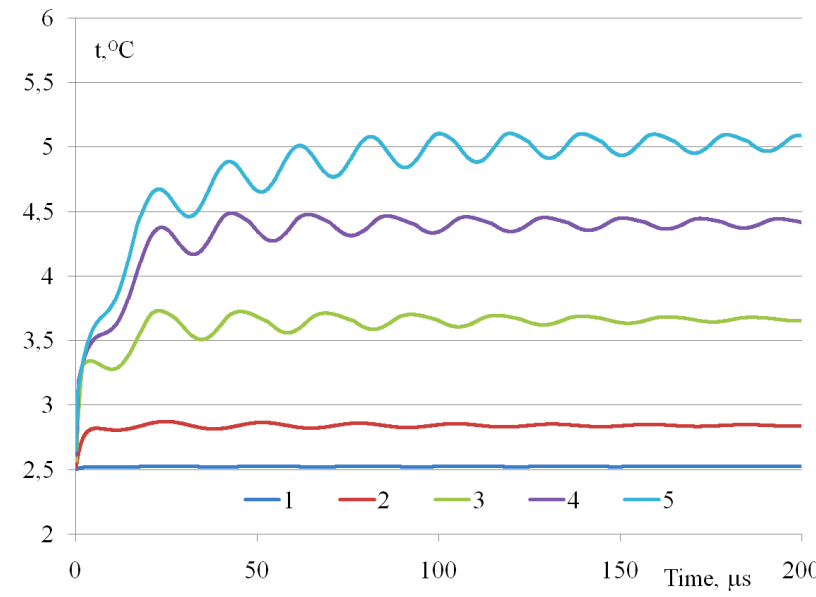

Fig. 6. Gas temperature in a bubble at different initial pressures ( $\mathrm{P}$ bar) $1-P=P_{\min } ; 2-P=P_{\min }+0.1$;

$3-P=P_{\min }+0.5 ; 4-P=P_{\min }+1 ; 5-P=P_{\min }+1.5$ bar

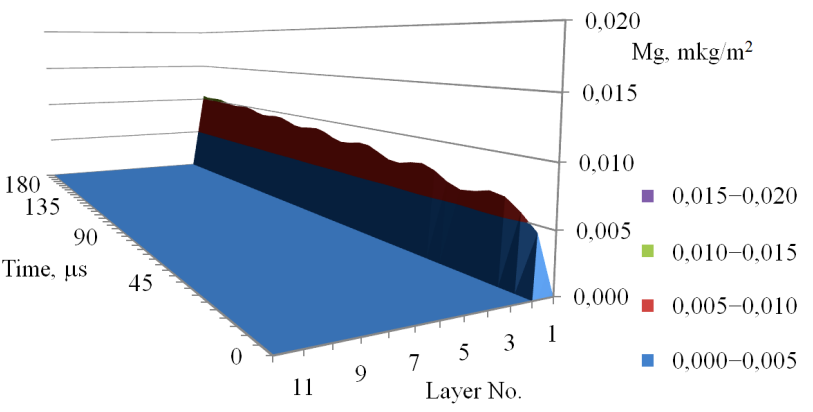

Fig. 7. Formation of hydrate at pressure $P=P_{\min }$

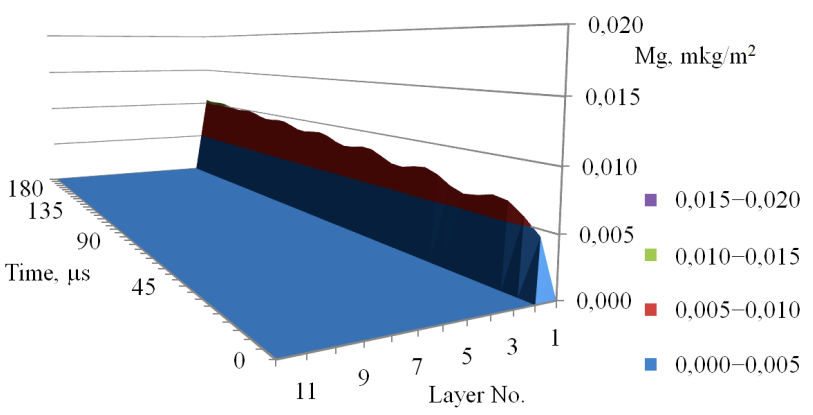

Fig. 8. Formation of hydrate at pressure $P=P_{\text {min }}+0.5$ bar

In general, Fig. 7-9 show an increase in the depth of hydrate formation with increase in pressure. However, the depth is very small and is about $0.06 \%$ of the radius of the bubble even for the 3rd layer. Such parameters accord with the formation of microcrystals of hydrates of the thickness of about 1 micron, which are obtained in laboratory conditions. They manifest themselves visually as "turbidity" of water through which bubbles of gas pass. Then the crystals grow together and form a macrostructure of a hydrate.

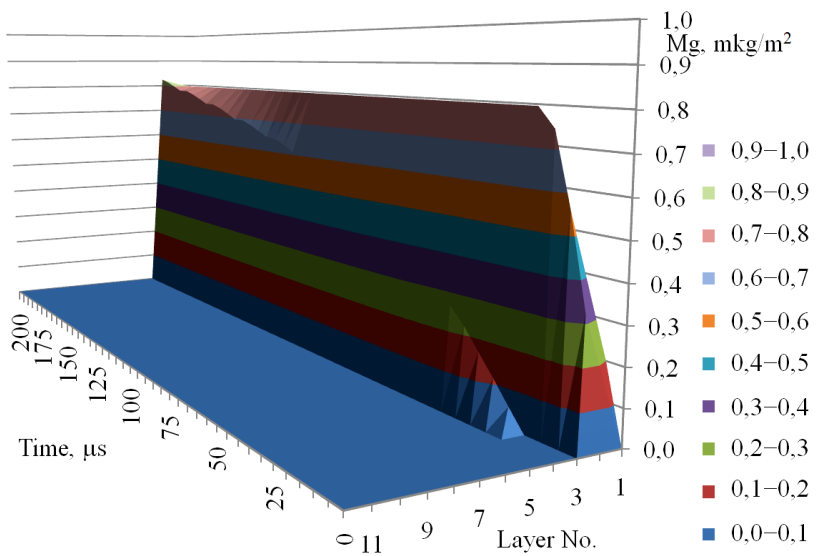

Fig. 9. Formation of hydrate at pressure $P=P_{\min }+1.5$ bar

\section{Discussion of results of mathematical modeling of} hydrate formation on the surface of a gas bubble

Heating of liquid layer bubbles, which are closest to the surface, with simultaneous cooling of the gas occurs firstly at initial temperature of gas $+3{ }^{\circ} \mathrm{C}$ (Fig. 1). The process of hydrate formation at excess gas temperature does not occur. Calculations show that the hydrate begins to form after sufficient cooling of a gas in a bubble only. This explains a lack of hydrate formation during the first $100 \mu \mathrm{s}$. The cooling process is superimposed on fading vibrations of a bubble. Then the temperature stabilizes due to a heat generation caused by hydrate formation. A thermal wave penetrates into water by $2.4 \%$ of a radius of a bubble in $200 \mu$ s. The total amount of hydrate is small and the process is very ineffective under such conditions.

When the temperature of a gas in a bubble decreases, the situation changes radically. Fig. 3 shows the temperature regime of liquid layers at the initial temperature of $0{ }^{\circ} \mathrm{C}$. The amount of formed hydrate also increases significantly, Fig. 4. However, as shown in Fig. 4, hydrate is formed only in the first, the thinnest, layer of water. Its thickness is about $0.01 \%$ of the radius of the bubble. In addition, it may partially (dissociate) decompose during oscillations.

It is necessary to cool gas to form a hydrate in deeper layers of the liquid. The results of the calculation at the initial temperature of $-5{ }^{\circ} \mathrm{C}$ show a rapid "freezing" of the $1 \mathrm{st}$ and 2nd layers and a partial freezing of the 3rd layer of the liquid. Moreover, the first and second "freeze" occur in the first 5 microseconds, and the process continues for all 200 microseconds for the 3rd layer. Hydrate formation at the initial temperature of $-10{ }^{\circ} \mathrm{C}$ proceeds in a similar manner. Moreover, the third layer freezes more intensively than in the previous case, but the amount of hydrate changes little. The reason for this is a deterioration of the drainage of heat from the hydrate formation region.

If to accept the mass of the formed hydrate at a gas temperature of $+2{ }^{\circ} \mathrm{C}$ per unit, then for different temperatures, a relative amount of hydrate will have the form of dependence shown in Fig. 10. When the initial temperature of a gas mixture increases to $+3{ }^{\circ} \mathrm{C}$ and the pressure is constant, the hydrate formation process almost stops. There is a uniform increase in a rate of hydrate formation up to temperature of $-5^{\circ} \mathrm{C}$. Reduce in the initial temperature of a gas mixture below $-5{ }^{\circ} \mathrm{C}$ does not lead to a significant acceleration of hydrate formation. 


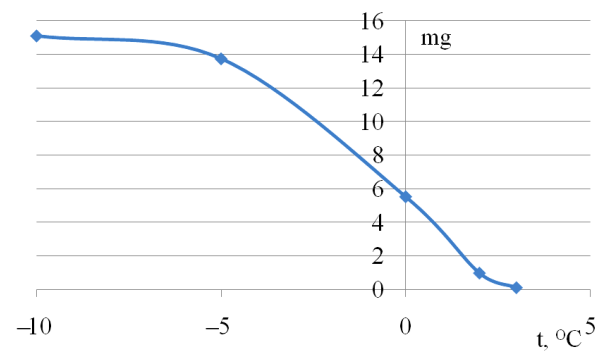

Fig. 10. Influence of gas temperature on hydrate formation

Each gas composition will have an "own" line, which is similar to the curve on Fig. 10, at different pressure values. Their determination is very important for optimization of technological processes and requires additional investigations.

\section{Conclusions}

1. We supplemented a mathematical model of transition thermodynamic processes of an oscillating gas bubble with a description of diffusion processes on the interphase gas-water surface. In addition, a model takes into account that the composition of a gas mixture may include a hydrate forming component, which can participate in the formation of gas hydrate under certain thermobaric conditions.

2. We performed calculations of transition thermodynamic processes occurring inside and on a surface of an oscillating gas bubble. It was established that the initial temperature of a steam-gas medium of a bubble influences the process of hydrate formation significantly. The most intense hydrate formation takes place at the region of initial heating of a steam-gas medium of a bubble. There is a local increase in the temperature of liquid during hydrate formation, and after due to a heat exchange and steam-gas medium of a bubble. We observe the maximum rate of formation of hydrates during a period of gas heating in a bubble. This period has a short duration of $2 \div 40 \mu$ s. However, it is the most productive.

We observe oscillations (fading oscillations) of a bubble after the heating period. The starting mechanism for the oscillations is a temperature difference between a gas steam bubble medium and hydration temperature determined by pressure of a medium. The growth of gas temperature leads to an increase in bubble pressure, which results in the process of increasing of its diameter. Hydrate formation occurs during action of oscillations also, but we can observe its dissociation at different moments. This is especially noticeable at not too low gas temperatures $\left(+3 \div 0{ }^{\circ} \mathrm{C}\right)$.

The oscillations fade gradually and the hydration process is supported by the removal of heat into outer layers of liquid due to the friction in viscous liquid. Since this process is limited to a significant heat transfer resistance of both the liquid and the formed hydrate layers, the rate of formation of hydrates reduces sharply. The performed calculations show that there is an optimal initial gas temperature in a bubble for hydrate formation. This temperature is $-5{ }^{\circ} \mathrm{C}$ for a pressure of "winter" propane-butane mixture of 3.4 bar.

3 . Results of the studies showed that an increase in pressure positively affects the process of hydration, but it is limited to the condensation region of components of the propane-butane mixture. Thus, it is technologically necessary to reduce gas temperature in a bubble and increase pressure to accelerate hydrate formation. The optimal values of pressure and temperature can depend on the composition of gas, the temperature of liquid and the size of bubbles. It is necessary to conduct additional research to determine them.

\section{References}

1. Yakushev, V. S. Sovremennoe sostoyanie gazogidratnyh tekhnologiy [Text] / V. S. Yakushev, V. G. Kvon, Yu. A. Gerasimov, V. A. Istomin. - Moscow: OOO «IRC Gazprom», 2008. - 88 p.

2. Stern, L. A. Temperature, pressure, and compositional effects on anomalous or "self" preservation of gas hydrates [Text] / L. A. Stern, S. Circone, S. H. Kirby, W. B. Durham // Canadian Journal of Physics. - 2003. - Vol. 81, Issue 1-2. - P. 271-283. doi: 10.1139/ p03-018

3. Mosin, O. V. Fiziko-himicheskie osnovy opresneniya morskoy vody [Text] / O. V. Mosin // Soznanie i fizicheskaya real'nost'. 2012. - Issue 1. - P. 19-30.

4. Takeya, S. Self-preservation effect and dissociation rates of CH4 hydrate [Text] / S. Takeya, T. Ebinuma, T. Uchida, J. Nagao, H. Narita // Journal of Crystal Growth. - 2002. - Vol. 237-239. - P. 379-382. doi: 10.1016/s0022-0248(01)01946-7

5. Pavlenko, A. Basic principles of gas hydrate technologies [Text] / A. Pavlenko, H. Koshlak, B. Usenko // Metallurgical and Mining Industry. - 2014. - Issue 3. - P. 60-65.

6. Behkish, A. Novel correlations for gas holdup in large-scale slurry bubble column reactors operating under elevated pressures and temperatures [Text] / A. Behkish, R. Lemoine, R. Oukaci, B. I. Morsi // Chemical Engineering Journal. - 2006. - Vol. 115, Issue 3. P. 157-171. doi: 10.1016/j.cej.2005.10.006

7. Shahrzad, H. Dynamic Simulation of Gas Hydrate Formation in an Agitated Three-Phase Slurry Reactor [Text] / H. Shahrzad, M. Arturo, S. Phillip // The 12th International Conference on Fluidization - New Horizons in Fluidization Engineering. - 2007. P. 329-336.

8. Kulinchenko, V. R. Peredumovy stvorennia matematychnoi modeli - osnovni polozhennia i rivniannia rukhu Releia [Text] / V. R. Kulinchenko, V. L. Zavialov, T. H. Mysiura // Naukovi pratsi Natsionalnoho universytetu kharchovykh tekhnolohyi. - 2007. Issue 22. - P. 36-41.

9. Il'mov, D. N. Teplofizicheskie processy pri szhatii parovogo puzyr'ka v zhidkom uglevodorode na osnove gomobaricheskoy modeli [Text] / D. N. Il'mov, S. G. Cherkasov // Teplofizika vysokih temperatur. - 2012. - Vol. 50, Issue 5. - P. 676-684. - Available at: http://www.mathnet.ru/links/a96357749ddc8f7cc5ff3dcf53c5493a/tvt396.pdf 
10. Shagapov, V. Sh. K teorii rosta parovyh puzyr'kov v metastabil'noy zhidkosti [Text] / V. Sh. Shagapov, V. V. Koledin // Teplofizika vysokih temperatur. - 2013. - Vol. 51, Issue 4. - P. 543-551. doi: 10.7868/s0040364413040212

11. Aktershev, S. P. Modelirovanie vskipaniya metastabil'noy zhidkosti pri nalichii frontov ispareniya [Text] / S. P. Aktershev, V. V. Ovchinnikov // Sovremennaya nauka: issledovaniya, idei, rezul'taty, tekhnologi. - 2013. - Issue 1. - P. 77-82.

12. Veretel'nik, T. I. Matematicheskoe modelirovanie kavitacionnogo potoka zhidkosti v himiko-tekhnologicheskoy sisteme [Text] / T. I. Veretel'nik, Yu. N. Difuchin // Visnyk ChDTU. - 2008. - Issue 3. - P. 82-85.

13. Kulinchenko, V. R. Osnovy matematicheskogo modelirovaniya dinamiki rosta parovoy fazy [Electronic resource] / V. R. Kulinchenko // Available at: http://dspace.nuft.edu.ua/jspui/bitstream/123456789/2224/1/21.pdf

14. Nigmatulin, R. I. Dinamika i teplomassoobmen parogazovyh puzyr'kov s zhidkost'yu [Text] / R. I. Nigmatulin, N. S. Habeev // Nekotorye voprosy mekhaniki sploshnoy sredy. - Moscow: In-t mekhaniki MGU, 1978. - P. 229-243.

15. Dolinskiy, A. A. Teoreticheskoe obosnovanie principa diskretno-impul'snogo vvoda energii. Model' dinamiki odinochnogo parovogo puzyr'ka [Text] / A. A. Dolinskiy, G. K. Ivanickiy // Prom. teplotekhnika. - 1995. - Vol. 17, Issue 5. - P. 3-28.

16. Pavlenko, A. A study of phase transition processes features in liquid-gas systems [Text] / A. Pavlenko, B. Kutnyi, N. Abdullah // Eastern-European Journal of Enterprise Technologies. - 2017. - Vol. 4, Issue 5 (88). - P. 43-50. doi: 10.15587/17294061.2017.108535

17. Lambert, J. D. Computational Methods in Ordinary Differential Equations [Text] / J. D. Lambert. - Wiley, Chichester, 1991. $304 \mathrm{p}$.

18. Butcher, J. C. Numerical Methods for Ordinary Differential Equations [Text] / J. C. Butcher. - New York: John Wiley \& Sons, 2008. - $482 \mathrm{p}$.

19. Kushnir, S. V. Barbotazhni khimichni efekty: yikh vydy, mekhanizmy vynyknennia ta heokhimichni proiavy [Text] / S. V. Kushnir, M. V. Kost, R. P. Kozak // Voda i vodoochysni tekhnolohyi. Naukovo-tekhnichni visti. - 2016. - Issue 3. - P. 30-47.

20. Semenov, M. E. Sintez gidratov gazov laboratornyh usloviyah. Ch. II [Text] / M. E. Semenov, E. Yu. Shic // Tekhnicheskie nauki ot teorii k praktike: sb. st. po mater. XVII mezhdunar. nauch.-prakt. konf. - Novosibirsk: SibAK, 2013. - P. 55-61.

21. Okutani, K. Surfactant effects on hydrate formation in an unstirred gas/liquid system: An experimental study using methane and sodium alkyl sulfates [Text] / K. Okutani, Y. Kuwabara, Y. H. Mori // Chemical Engineering Science. - 2008. - Vol. 63, Issue 1. P. 183-194. doi: 10.1016/j.ces.2007.09.012 